\title{
Yoga as Advanced Cognitive Training: How Kirtan Kriya In Kundalini Yoga Changes the PTSD Brain
}

\author{
Erika Sales ${ }^{1}$, and Ying-hui $\mathrm{Chou}^{2 *}$ \\ ${ }^{1}$ Teachers College, Columbia University, USA \\ ${ }^{2}$ Department of Psychology and Evelyn F McKnight Brain Institute, University of Arizona, USA
}

Submission: July 27, 2019; Published: September 03, 2019

*Corresponding author: Ying-hui Chou, Brain Imaging and TMS Laboratory, Department of Psychology, University of Arizona, USA Sc D, Evelyn F McKnight Brain Institute, Arizona Center on Aging, and BIO5 Institute, University of Arizona, USA

\begin{abstract}
Research on yoga interventions for post-traumatic stress disorder (PTSD) is plentiful, but none to date have studied the neural effects and benefits of a yogic practice on the default mode network (DMN) in PTSD. Common features of PTSD, such as mind-wandering and emotional dysregulation, are linked to altered neural functioning of the DMN due to initial trauma exposure. Symptom severity is also related to decreased neural connectivity of the DMN. This review explores Kirtan Kriya (KK), a series of repetitive, sequential movements that are synchronized with self-produced mantra in Kundalini Yoga, as a powerful intervention for symptoms and neural repair associated with altered functioning of the DMN due to PTSD. Future direction regarding the application of KK to PTSD are discussed.
\end{abstract}

Keywords: Focused Attention Meditation, Kirtan Kriya, Kundalini Yoga, PTSD, Post-Traumatic Stress Disorder, Default Mode Network

\section{Introduction}

Post-traumatic stress disorder (PTSD) is a mental illness caused by exposure to threat, or involvement in a traumatic event [1]. Symptoms include mind-wandering, rumination, depression, flashbacks, and anxiety that are associated with the initial trauma stimuli $[2,3]$. In recent years, research has supported yoga as a strong alternative treatment for PTSD [410]. Yoga interventions have yielded similar benefits to that of psychotherapy for individuals with PTSD. While there are variations of yoga that can be applied to PTSD, certain yogic practices engage the same neural networks as mental training, which can strengthen the mind-body connection through practice overtime $[8,9,11]$. This article suggests that the practice of Kirtan Kriya (KK) in Kundalini Yoga (KY) may offer the most effective yogic exercise for brain change in the PTSD population through its recruitment of brain regions associated with the attentional network, default mode network, and mastery levels of learning.

$\mathrm{KY}$ is a distinct branch of yoga that uses repetitive, action orientated intervals called "kriyas" to target specific regions of the nervous and endocrine systems to positively affect mental, emotional, and physical change [12-18]. Kriyas are forms of focused attention meditation, which constantly redirect the practitioner to focus on a meditative object, visualization, or breath when distracted [16-18]. This form of sustained attention when combined with repetitive, self-produced sound and chronological, sequential movement, engage the default mode network (DMN) and recruits brain regions associated with skill mastery [19].

$\mathrm{KK}$, in particular, is a kriya that uses repetitive, sequential finger-movements coordinated with self-produced mantra while sitting in easy-pose with closed eyes for 11-12 minutes [11-18,20-23]. To begin KK, an individual sits with their eyes closed and focuses on the horizon of darkness between their brow-point. Next, they repetitively chant "Sa, Ta, Na, Ma" while chronologically touching their fingers to each sound and continuously repeating the movement for 11-12 minutes [22]. The mantra "Sa, Ta, Na, Ma" is defined as "birth, life, death, and rebirth" [15]. The movement is as follows: the individual touches their first finger to their thumb and chants "Sa", their second finger to their thumb and chants "Ta", their third finger to their thumb and chants "Na", and their fourth finger to the thumb and chants "Ma". During the 11 to 12 minutes, the mantra is whispered, spoken out loud, and repeated silently in 3-4-minute segments [11]. This movement occurs in both hands at the same time. 
Yogic philosophy explains the benefits of KK as producing an increased awareness of sensation, equanimity, and consciousness $[11,15,18,22]$. Neurological observations include increased neural connectivity, cerebral blood flow, and DMN deactivations as sustainable benefits [24]. In line with these observations, focused attention meditation engages the prefrontal cortex, anterior cingulate cortex, thalamus, dorsolateral prefrontal cortex, ventrolateral prefrontal cortex, insula, and precuneus $[12,18,22,23,25]$. These regions are implicated in the DMN's role of attention sustainment during KK and associated with selfreferential processing, mind wandering, and internal narratives $[12,15,22,23,25-28]$.

Researchers studying the effects of a single KY class observed a decrease in perceived stress following the conclusion of one class session [17]. Other researchers studying the effect of $\mathrm{KK}, \mathrm{KY}$, or $\mathrm{KK}$ as a component of $\mathrm{KY}$ have reported elevated mood, enhanced cognitive performance, and stronger feelings of empathy associated with increased neural connectivity in regions linked to the DMN following 8 week and 12 week practices $[3,11,22,23,25]$. In healthy individuals, the DMN functions as relatively inactive when engaging in a task because it is taking in information, active when at rest, and decreasing in activity during tasks requiring increased or constant attention $[12,18,23,25,29]$. In PTSD, the DMN functionality is altered and decreased connectivity between the DMN and the attentional control networks has been observed [2]. This results in activity peaks of the DMN during resting state when an individual is unaware of mind wandering, which leads to disengagement in daily activities, rumination, depression, and other symptoms common to PTSD [2,30]. Alternatively, increased connectivity between the DMN and attentional networks is correlated with decreased hyperarousal and avoidant behavior observed in mindfulness-based training research studying the PTSD population [2].

\section{How KK Initiates Changes in the PTSD Brain}

Mantra is Sanskrit for "mind" (manas) "tools" (tra) and is a word, sequence of words, or self-produced sound used to focus attention to create a state of equanimity [26,31]. Mantra repetition has been shown to slow racing thoughts, decrease psychological stress, ease sleep disturbances, and improve emotional intelligence in PTSD [32]. In a study researching the effects of six 90-minute, weekly sessions of mantra repetition in veterans with PTSD, an increase of calmness and sense of grounding was experienced by all participants [32]. Interestingly, many participants in this study referred to the mantra as a "security blanket" they used when distressed, before bed, or in the morning to begin the day [33]. A "security blanket" is typically associated with an attachment object that relieves stress and anxiety [34]. Since attachment objects are considered to be effective when in one's possession or presence, this suggests that being in possession and control of a mantra has the potential to evoke the same benefits of an attachment object. Benefits include a greater attention span, resilience, and mediation of arousal.

Mantra repetition is linked to deactivations in the DMN regions of the precuneus, posterior cingulate cortex (PCC), anterior cingulate cortex, and medial prefrontal cortex [29]. Deactivation in these regions is associated with decreased selfjudgment and emotional narratives, resulting in heightened awareness in the present moment. The PCC, a central region of the DMN, acts a switchboard that mediates a person's focus towards external (engaging in real-time tasks) or internal (memory retrieval, ruminating) engagement during daily activities [35]. In PTSD, the PCC connectivity to the dorsolateral prefrontal cortex (DLPFC), an area of the DMN associated with emotion and stress regulation, is weakened [2]. During KK, the PCC is constantly "exercised" in order to sustain the cognitive control needed for focused attention and suppression of distracting sensory inputs [28].

During KK mantra recitation, an individual must synchronize their self-produced sound to sequential, repetitive finger movements $[11,18]$. These voluntary movements activate regions of the brain associated with embodiment and psychological resilience, a key factor influencing symptom severity and proclivity to developing PTSD [12,14,15,24,25,36,37]. The DLPFC, in particular, was activated during self-initiated finger movements in Jenkin et al. [38] study, indicating that concentration on self-produced cues correlated with movements.

The DLPFC acts as a gate to the DMN and mediator between sensory areas [2,38-41]. It is associated with shifting and sustaining attentional awareness to the present moment [3841]. The DLPFC also plays a significant role in decision making processes and the selection of socially appropriate behavior $[23,36]$. Increased connectivity between the DMN and DLPFC is linked to enhanced emotional regulation and ability to shift awareness from introspective to extrospective states. In PTSD, increases in DLPFC connectivity correlate with decreases in hyperarousal [2]. This results in significant changes in impulsivity, aggressiveness, hypersensitivity, and hyperexcitability [42].

Long-term training in sequential movement has been linked to the same neurological changes observed when reaching "expert" level of performance for a given task [19]. During a 2011 study researching the change in resting state connectivity of the motor system during a 4-week sequential finger movement practice, increased connectivity in the right postcentral gyrus and bilateral supramarginal gyri was observed after 2-weeks of learning the practice [37]. Increased cerebral blood flow and neural connectivity in the right precentral gyrus, left precentral gyrus, and parietal regions were observed as sustained changes following the conclusion of the 4 -week study. Ma et al. associated these activations with "motor cognition", which refers to a state of embodiment. Motor cognition is the process of knowledge 
informing action whereby the motor system assists in the learning process behind understanding a movement. This type of training is considered "domain specific" because it involves motor and mental learning [19]. In embodiment, an individual interprets the meaning of words and expresses the interpretation [43]. Activations associated with embodiment were observed in KK where participants experienced greater self-awareness, empathy, and self- expression following practice $[14,23,25,44]$.

Overall, studies using KK interventions have consistently observed positive effects on emotional health $[3,11,23,25,40]$. Individuals with PTSD often fail to recognize internally produced cues because they operate in constant state of anticipation [45]. In an 8-week fMRI study researching the effect of KK on mood and anxiety on individuals with memory loss, cerebral blood flow increases to the right amygdala and right caudate correlated with improved mood and reduced depression [25]. Behavioral improvements occurring with increased cerebral blood flow to the amygdala are also linked to enhanced memory, which is illustrative of gaining a deeper capacity for emotional understanding that effects mood. These benefits are even more pronounced for experienced meditators. In PTSD, increased cerebral blood flow to the amygdala strengthens the downregulation process when confronted by trauma stimuli so an individual's capacity for emotional processing and fear extinction is not impaired by previously learned emotional narratives [46].

Abnormal functioning of the amygdala has been observed in PTSD as a long-term change in the brain's response to stress and anxiety [47]. During hyper-arousal in PTSD, there is an increased activation in the amygdala and decreased activation in the prefrontal cortex and the anterior cingulate cortex [48]. In Newberg's 2010 study, activity in the amygdala decreased nearly 5 times more from its pre-meditative state in the group practicing KK [22]. Newberg's 2010 study also observed increased cerebral blood flow to the prefrontal lobe regions associated with executive functioning and attentional processes. Reduced connectivity in these regions is associated with impaired fear response, fear learning, and fear extinction [49]. This results in avoidant behavior, dissociation, and decreased social interaction in PTSD.

\section{Conclusion and Future Direction}

Previous studies have investigated the effects of various branches of yoga on PTSD, including Sudarshan Kriya yoga (SKY), Kripalu-based yoga, trauma-informed yoga, Krishnamacharya Healing and Yoga, and KY, but none to date have studied the effects of KK on neural connectivity or brain plasticity in individuals with PTSD $[4-6,10]$. Research focused on the benefits of a complex focused attention meditation like $\mathrm{KK}$ is valuable when considering the disruption and anxiety caused by intrusive thoughts and flashbacks, as well as the inability to sustain focus symptomatic of PTSD [2]. Further research is also needed to explore the comparison between the effects of mantra with meaning and the effect of Sanskrit words (in the circumstance where the practitioner is unaware of the meaning) on the brain. For KK, this research would center on the question of whether it is the power of the sound in the KK mantra, the movement of the tongue against the upper palate, or the meaning of the KK mantra that affects the brain [15]. It would also be useful to study KK for a period longer than 12-weeks on a group.

It also worth noting that to date, only four studies researching the neural and cognitive benefits of KK have defined the meaning of the KK mantra in their study $[11,12,18,50]$. Eyre et al.'s 2017 study [11] defined the mantra and used KK as part of a larger 60-minute KY session for participants over 55-years old with cognitive impairment. The study concluded that the KK component provided "mind exercise" while the KY provided physical exercise $[11,12,18,50]$. When mantra carries meaning as it does in $\mathrm{KK}$, it integrates spirituality into the practice and enables a practitioner to experience feelings of transcendence and connectedness to a greater life force [51]. This can lead to a deeper understanding of emotions and cognitive reframing of traumatic events. These elements influence psychological resilience, a key factor affecting proclivity to PTSD and symptom severity [36].

Lastly, none of these studies nor any yoga research to date focusing on neurological, cognitive, or behavioral changes have considered the effect of meditating or practicing yoga on a full or empty stomach, or a general timed duration from eating to practicing yoga when collecting data. This consideration could provide more definitive results on symptom relief and cognitive performance post-practice.

\section{References}

1. National Center for PTSD (2017) United States Department of Veterans Affairs.

2. King AP, Block SR, Sripada RK, Rauch S, Giardino N, et al. (2016) Altered Default Mode Network (Dmn) Resting State Functional Connectivity Following a Mindfulness-Based Exposure Therapy for Posttraumatic Stress Disorder (Ptsd) in Combat Veterans of Afghanistan and Iraq. Depress Anxiety 33(4): 289-99.

3. Innes KE, Selfe TK, Khalsa DS, Kandati S (2016) Effects of Meditation versus Music Listening on Perceived Stress, Mood, Sleep, and Quality of Life in Adults with Early Memory Loss: A Pilot Randomized Controlled Trial. J Alzheimers Dis 52(4): 1277-1298.

4. Walker J 3rd, Pacik D (2017) Controlled Rhythmic Yogic Breathing as Complementary Treatment for Post-Traumatic Stress Disorder in Military Veterans: A Case Series. Med Acupunct 29(4): 232-238.

5. Mitchell KS, Dick AM, DiMartino DM, Smith BN, Niles B, et al. (2014) A pilot study of a randomized controlled trial of yoga as an intervention for PTSD symptoms in women. J Trauma Stress 27(2): 121-128.

6. Staples JK, Hamilton MF, Uddo MA (2013) Yoga program for the symptoms of post-traumatic stress disorder in veterans. Mil Med 178(8): 854-860.

7. Descilo T, Vedamurtachar A, Gerbarg PL, Nagaraja D, Gangadhar BN, et al. (2010) Effects of a yoga breath intervention alone and in combination with an exposure therapy for post-traumatic stress disorder and depression in survivors of the 2004 South-East Asia tsunami. Acta Psychiatr Scand 121(4): 289-300. 
8. Price M, Spinazzola J, Musicaro R, Turner J, Suvak M, et al. (2017) Effectiveness of an Extended Yoga Treatment for Women with Chronic Posttraumatic Stress Disorder. J Altern Complement Med 23(4): 300309.

9. McCarthy L, Fuller J, Davidson G, Crump A, Positano S, et al. (2017) Assessment of yoga as an adjuvant treatment for combat-related posttraumatic stress disorder. Australas Psychiatry 25(4): 354-357.

10. van der Kolk BA, Stone L, West J, Rhodes A, Emerson D, et al. (2014) Yoga as an adjunctive treatment for posttraumatic stress disorder: a randomized controlled trial. J Clin Psychiatry 75(6): e559-65.

11. Eyre HA, Siddarth P, Acevedo B, Van Dyk K, Paholpak P, et al. (2017) A randomized controlled trial of Kundalini yoga in mild cognitive impairment. Int Psychogeriatr 29(4): 557-567.

12. Eyre HA, Acevedo B, Yang H, Siddarth P, Van Dyk K, et al. (2016) Changes in Neural Connectivity and Memory Following a Yoga Intervention for Older Adults: A Pilot Study. J Alzheimers Dis 52(2): 673-84.

13. Yang H, Leaver AM, Siddarth P, Paholpak P, Ercoli L, et al. (2016) Neurochemical and Neuroanatomical Plasticity Following Memory Training and Yoga Interventions in Older Adults with Mild Cognitive Impairment. Front Aging Neurosci 8: 277.

14. Jindani FA, Khalsa GF (2015) A Yoga Intervention Program for Patients Suffering from Symptoms of Posttraumatic Stress Disorder: A Qualitative Descriptive Study. J Altern Complement Med 21(7): 401408 .

15. Khalsa DS, Amen D, Hanks C, Money N, Newberg A (2009) Cerebral blood flow changes during chanting meditation. Nucl Med Commun 30(12): 956-961.

16. Shannahoff-Khalsa DS (2004) An introduction to Kundalini yoga meditation techniques that are specific for the treatment of psychiatric disorders. J Altern Complement Med 10(1): 91-101.

17. García-Sesnich JN, Flores MG, Ríos MH, Aravena JG (2017) Longitudinal and Immediate Effect of Kundalini Yoga on Salivary Levels of Cortisol and Activity of Alpha-Amylase and Its Effect on Perceived Stress. Int Yoga 10(2): 73-80.

18. Lavretsky H, Epel ES, Siddarth P, Nazarian N, Cyr NS, et al. (2013) A pilot study of yogic meditation for family dementia caregivers with depressive symptoms: effects on mental health, cognition, and telomerase activity. Int J Geriatr Psychiatry 28(1): 57-65.

19. Debarnot U, Sperduti M, Di Rienzo F, Guillot A (2014) Experts bodies, experts minds: How physical and mental training shape the brain Front Hum Neurosci 8: 280.

20. Black DS, Cole SW, Irwin MR, Breen E, St Cyr NM, et al. (2013) Yogic meditation reverses NF-kappaB and IRF-related transcriptome dynamics in leukocytes of family dementia caregivers in a randomized controlled trial. Psychoneuroendocrinology 38(3): 348-55.

21. Khalsa D S, Newberg A, (2011) In Enhancing Cognitive Fitness in Adults (eds P. Hartman-Stein \& A. LaRue) 419-431.

22. Newberg AB, Wintering N, Khalsa DS, Roggenkamp H, Waldman MR (2010) Meditation effects on cognitive function and cerebral blood flow in subjects with memory loss: a preliminary study. J Alzheimers Dis 20(2): 517-526.

23. Wang DJ, Rao H, Korczykowski M, Wintering N, Pluta J, et al. (2011) Cerebral blood flow changes associated with different meditation practices and perceived depth of meditation. Psychiatry Res 191(1): 60-67.

24. Smoski MJ, McCLintock A, Keeling L (2016) Mindfulness training for emotional and cognitive health in late life. Current Behavioral
Neuroscience Reports 3(4): 301-307

25. Moss AS, Wintering N, Roggenkamp H, Khalsa DS, Waldman MR, et al (2012) Effects of an 8-week meditation program on mood and anxiety in patients with memory loss. J Altern Complement Med 18(1): 48-53.

26. Berkovich-Ohana A, Wilf M, Kahana R, Arieli A, Malach R (2015) Repetitive speech elicits widespread deactivation in the human cortex: the "Mantra" effect? Brain Behav 5(7): e00346.

27. Lee TM, Leung MK, Hou WK, Tang JC, Yin J, et al. (2012) Distinct neural activity associated with focused-attention meditation and lovingkindness meditation. PLoS One 7(8): e40054.

28. Manna A, Raffone A, Perrucci MG, Nardo D, Ferretti A, et al. (2010) Neural correlates of focused attention and cognitive monitoring in meditation. Brain Res Bull 82(1-2): 46-56.

29. Simon R, Pihlsgard J, Berglind U, Soderfeldt B Engstrom M (2017) Mantra meditation suppression of default mode beyond an active task: A pilot study. Journal of Cognitive enhancement 1(2): 219-227.

30. Garrison KA, Scheinost D, Worhunsky PD, Elwafi HM, Thornhill TA, et al. (2013) Real-time fMRI links subjective experience with brain activity during focused attention. Neuroimage 81: 110-118.

31. Lolla A (2018) Mantras Help the General Psychological Well-Being of College Students: A Pilot Study. J Relig Health 57(1): 110-119.

32. Bormann JE, Hurst S, Kelly A (2013) Responses to Mantram Repetition Program from Veterans with posttraumatic stress disorder: a qualitative analysis. J Rehabil Res Dev 50(6): 769-84.

33. Bormann JE, Oman D, Kemppainen JK, Becker S, Gershwin M, et al. (2006) Mantram repetition for stress management in veterans and employees: a critical incident study. J Adv Nurs 53(5): 502-512.

34. Passman RH (1977) Providing attachment objects to facilitate learning and reduce distress: Effects of mothers and security blankets. Developmental Psychology 13(1): 25-28.

35. Hove MJ, Stelzer J, Nierhaus T, Thiel SD, Gundlach C, et al. (2016) Brain Network Reconfiguration and Perceptual Decoupling During an Absorptive State of Consciousness. Cereb Cortex 26(7): 3116-3124.

36. Hourani LL, Jason Williams, Valerie Forman-Hoffman, Marian E. Lane, Belinda Weimer, et al. (2012) Influence of spirituality on depression, posttraumatic stress disorder, and suicidality in active duty military personnel. Depress Res Treat 425463: 9.

37. Ma L, Narayana S, Robin DA, Fox PT, Xiong J (2011) Changes occur in resting state network of motor system during 4 weeks of motor skill learning. Neuroimage 58(1): 226-233.

38. Jenkins IH, Jahanshahi M, Jueptner M, Passingham RE, Brooks DJ (2000) Self-initiated versus externally triggered movements. II. The effect of movement predictability on regional cerebral blood flow. Brain 123(Pt 6): 1216-28.

39. Garrison KA, Zeffiro TA, Scheinost D, Constable RT, Brewer JA (2015) Meditation leads to reduced default mode network activity beyond an active task. Cogn Affect Behav Neurosci 15(3): 712-720.

40. Taylor VA, Daneault V, Grant J, Scavone G, Breton E, et al. (2013) Impact of meditation training on the default mode network during a restful state. Soc Cogn Affect Neurosci 8(1): 4-14.

41. Engström M, Pihlsgård J, Lundberg P, Söderfeldt B (2010) Functional magnetic resonance imaging of hippocampal activation during silent mantra meditation. J Altern Complement Med 16(12): 1253-1258.

42. Doll A, Hölzel BK, Boucard CC, Wohlschläger AM, Sorg C (2015) Mindfulness is associated with intrinsic functional connectivity between default mode and salience networks. Front Hum Neurosci 9: 
461.

43. Jirak D, Menz MM, Buccino G, Borghi AM, Binkofski F (2010) Grasping language--a short story on embodiment. Conscious Cogn 19(3): 711720 .

44. Jindani F, Turner N, Khalsa SB (2015) A Yoga Intervention for Posttraumatic Stress: A Preliminary Randomized Control Trial. Evid Based Complement Alternat Med 2015: 351746.

45. Simmons, A, Strigo IA, Matthews SC, Paulus MP, Stein MB (2009) Initial evidence of a failure to activate right anterior insula during affective set shifting in posttraumatic stress disorder. Psychosom Med 71(4): 373-377.

46. Nicholson AA, Rabellino D, Densmore M, Frewen PA, Paret C, et al (2017) The neurobiology of emotion regulation in posttraumatic stress disorder: Amygdala downregulation via real-time fMRI neurofeedback Hum Brain Mapp 38(1): 541-560.

47. Hölzel BK, Carmody J, Evans KC, Hoge EA, Dusek JA, et al. (2010) Stress reduction correlates with structural changes in the amygdala. Soc Cogn Affect Neurosci 38(1): 541-560.

48. Lanius RA, Bluhm RL, Coupland NJ, Hegadoren KM, Rowe B, et al. (2010) Default mode network connectivity as a predictor of posttraumatic stress disorder symptom severity in acutely traumatized subjects. Acta Psychiatr Scand 121(1): 33-40.

49. Miller DR, Hayes SM, Hayes JP, Spielberg JM, Lafleche G, et al. (2017) Default Mode Network Subsystems are Differentially Disrupted in Posttraumatic Stress Disorder. Biol Psychiatry Cogn Neurosci Neuroimaging 2(4): 363-371.

50. Pomykala KL, Silverman DH, Geist CL, Voege P, Siddarth P, et al. (2012) A pilot study of the effects of meditation on regional brain metabolism in distressed dementia caregivers. Aging health 8(5): 509-516.

51. Bormann JE1, Liu L, Thorp SR, Lang AJ (2012) Spiritual wellbeing mediates PTSD change in veterans with military-related PTSD. Int J Behav Med 19(4): 496-502.

Your next submission with Juniper Publishers
will reach you the below assets
- Quality Editorial service
- Swift Peer Review
- Reprints availability
- E-prints Service
- Manuscript Podcast for convenient understanding
- Global attainment for your research
- Manuscript accessibility in different formats
( Pdf, E-pub, Full Text, Audio)
- Unceasing customer service
Track the below URL for one-step submission
https://juniperpublishers.com/online-submission.php

